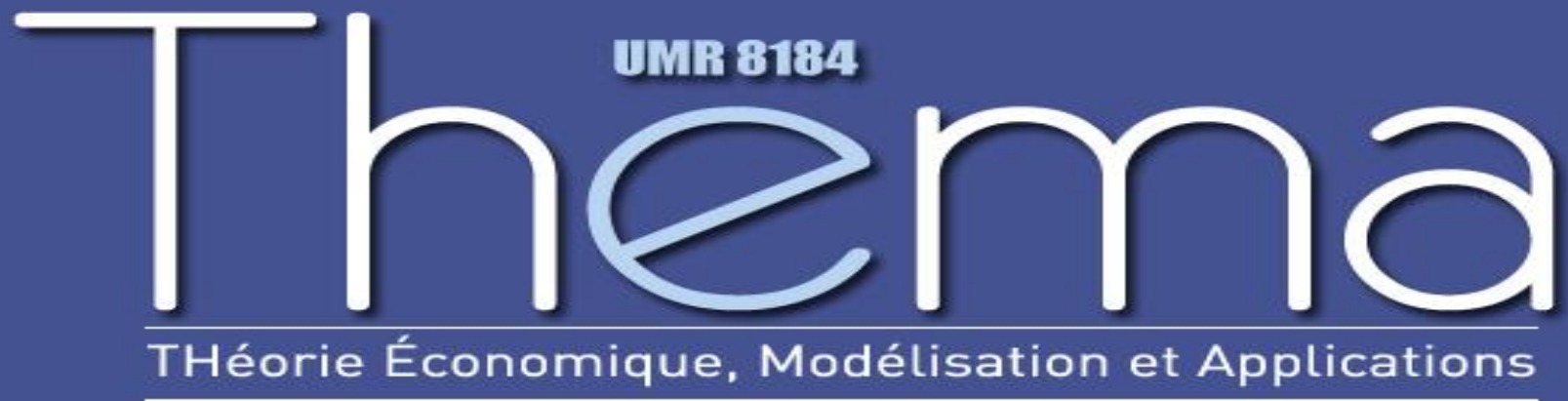

Thema Working Paper $\mathrm{n}^{\circ}$ 2013-08 Université de Cergy Pontoise, France

Job Polarization in Aging Economies

Eva Moreno - Galbis

Thepthida Sopraseuth

August, 2012 


\title{
Job Polarization in Aging Economies
}

\author{
Eva Moreno - Galbis * Thepthida Sopraseuth ${ }^{\dagger}$
}

August 11, 2012

\begin{abstract}
This paper extends on French data a previous finding on US data: employment growth has been more important in the lower and upper tail of the job quality distribution. The originality of the paper is to argue that the diffusion of ICT cannot explain alone the polarization at the lower tail of the distribution. However, when combined with population aging, our framework predicts a progressive concentration of employment in the service sector (bottom tail of the job quality distribution). This results from a purely demand shift, since, as revealed by our estimations goods and services are complementary for seniors. The decrease in the relative price of goods induced by ICT diffusion is thus associated with an increased demand for services if the proportion of seniors is increasing.
\end{abstract}

JEL Codes : J14, J21, J24, O33

Keywords : Job Polarization, Occupational Structure, Aging

${ }^{*}$ Corresponding author. GRANEM (University of Angers), IRES (Catholic University of Louvain) and GAINS-TEPP (University of Maine). Email: Eva.morenogalbis@univ-angers.fr, Eva.Moreno-Galbis@univlemans.fr. Tel: +33243833656

${ }^{\dagger}$ University of Maine (GAINS-TEPP, Pres UNAM) and Cepremap. Email : thepthida.sopraseuth@univlemans.fr. We thank François Langot, Bruno Decreuse, Ahmed Tritah, participants of Louvain Economic Seminar and participants of the T2M Conference for their comments. All remaining errors are ours. 


\section{Introduction}

This paper seeks to gain insights on the impact of aging on the recent labor market dynamics. The contribution of this paper is twofold. On the one hand, working with the French Household Budget Survey, we estimate the elasticity of substitution between goods and personnel services for senior households and young households. We find that goods and services are complements for seniors. With this evidence we proceed in a second step to estimate the contribution of population aging to the increased job polarization at the bottom of the wage distribution (job quality distribution) between 1993 and 2010. Using the French Labor Force Survey we start presenting evidence on the progressive polarization of the labor market between highly paid jobs and low-paid jobs. If the diffusion of Information and Communication Technologies (ICT) has fostered a reduction in the relative price of goods, we should observe an increase in the demand for services if goods and services are complements. Because goods and services are complement for seniors, while substitutes for young, population aging promotes an increase in the demand for services.

The economic literature points towards biased technological progress as the main factor behind the observed job polarization between "lousy and lovely" jobs (see Goos and Maning (2007), Maurin and Thesmar (2004) Autor, Levy, and Kearney (2006) or Spitz-Oener (2006)). The idea being that technology can replace human labor in routine tasks (manual or cognitive) but cannot replace human labor in non-routine tasks. Whereas routine tasks are mainly implemented by medium qualified workers (for example, book-keeping, clerical work and repetitive production tasks), non routine tasks can either be implemented by the least qualified workers (i.e. taxi driver, hairdresser, etc. referred to as "manual non routine tasks") or by the highest qualified workers (i.e. educated professionals and managers, referred to as "abstract tasks"). Because routine tasks are easily automated, new technologies have gradually replaced medium qualified workers in these tasks.

The gradual substitution of routine labor by machines has, on the one hand, improved the productivity of labor occupied in non-routine abstract positions, since new technologies facilitate and accelerate the access to abundant information and analysis. On the other hand, there is the appearance of a mass of jobless medium qualified workers. Part of this 
mass may remain unemployed ${ }^{1}$, whereas another part may be reallocated towards more labor demanding sectors. Obviously, in spite of the increased demand for qualified labor in abstract positions, there is a skill mismatch problem since medium qualified workers do not have the required qualification to apply to this type of non-routine jobs. They will have thus to reallocate towards manual non routine positions (see Goos and Maning (2007)). But why the demand for these jobs should rise?

The literature is far from an unanimous view concerning the reasons behind the increased demand for labor input in non routine manual jobs. Initially, most of the literature simply focused on the progression of wage inequalities. The works by Lemieux (2006) or Autor, Katz, and Kearney (2008) found that wage inequalities between the ninth and the fifth decile had increased more than wage inequalities between the ninth and the first decile, suggesting the existence of a rising demand for jobs at the top and at the bottom of the distribution or, at least, a decreasing demand for jobs at the middle of the distribution. Works by Autor, Levy, and Kearney (2006), Spitz-Oener (2006), Maurin and Thesmar (2004) or Goos and Maning (2007) confirmed the previous finding. These papers find that labor input in routine positions (middle of the wage distribution) has gradually been replaced by cheaper and more productive machines, which have also allowed to improve the productivity of labor input in abstract tasks (top of the wage distribution). The productivity of manual non routine tasks has remained unaffected. This type of positions are difficult to automate or outsource since they require interpersonal and environmental adaptability as well as direct physical proximity.

All of these papers agree on the fact that the automatization of routine tasks explains polarization at the top of the wage distribution. However, none of them really succeeds in explaining why novel technologies should have increased the demand for manual non routine labor. Manning (2004) simply remarks that employment of low-skilled workers is increasingly dependent on physical proximity to high-skilled as the work of low-skilled is increasingly concentrated in the non-traded sector. However the author does not investigate the reasons behind the potential rise in the share of high-skilled or in their income power. In a latter paper, Goos and Maning (2007), claim that medium qualified workers have been

\footnotetext{
${ }^{1}$ Cheron, Langot, and Moreno-Galbis (2011) show that the diffusion of new technologies has fostered a gradual increase in the relative unemployment rate of medium skilled workers.
} 
reallocated towards manual positions, but again no analysis is provided to justify the rise in the demand for low-skilled labor.

Mazzolari and Ragusa (2008) implement the first attempt to analyze a potential cause of the increasing demand for low-paid services. Their idea is that low-skilled are employed in nontradeable time-intensive services that are substitute for home production activities. Over the past decades, wage gains at the top of the wage distribution (skilled workers) have increased the opportunity cost of high-skilled for spending one hour in domestic activities. Rather than implementing by themselves this domestic production, high-skilled workers prefer now to buy these home services. The increase in the demand for low-paid services at the bottom of the wage distribution results then from a combination of a substitution effect (the opportunity cost of one hour of home production is now higher for high-skilled) and an income effect (because high-skilled are wealthier they can buy more services). This result contradicts the recent findings of Goos, Maning, and Salomons (2010). Based on 16 European countries the authors find that the routinization hypothesis is the most important factor behind the observed shifts in the employment structure. Little support is found for the hypothesis that changes in product demand are driven by income inequality effects ${ }^{2}$. They also conclude that globalization has decreased the demand for jobs that are offshorable, although the estimated impact is smaller relative to the impact of technological change. Autor and Dorn (2011) confirm these findings. More precisely they consider three potential explanation for the rise in service employment: 1) offshoring displaces low-skilled into non-offshorable service occupations; 2) rising income at the top of the wage distributions stimulated demand for inperson services, 3)rising returns to skill yield college-educated workers to substitute market for home-based production of household services. The authors find that these mechanisms are not empirically important drivers of polarization.

Autor and Dorn (2011) use the elasticity of substitution between goods and personnelservices to justify the progressive reallocation of workers replaced by machines in the good sector towards the personnel-service sector. According to these authors, if goods and services are sufficiently complementary, the progressive decrease in the relative price of goods (fostered by productivity gains linked to the diffusion of new technologies) should yield a

\footnotetext{
${ }^{2}$ Clark (1957) argued that the income elasticity of the demand for services is greater than unitary, in which case a general rise in income will tend to shift employment towards service-intensive occupations.
} 
rise in the demand for personnel-services. However, in their paper, Autor and Dorn (2011) do not justify why suddenly, over the past ten years, goods and personnel-services should have become complementary.

The originality of our paper lies in providing a potential explanation to the increase in the complementarity between goods and personnel-services proposed by Autor and Dorn (2011). Based on the French Household Budget Survey, we show that goods and services are complements for old people and substitutes for young people. Then, we claim that population aging can justify the change in the aggregate substitution/complementary relationship between goods and personnel-services. Population aging should lead to an increase in the demand for services in a context where the relative price of goods is falling due to the progressive substitution of labor by (cheaper) capital. Obviously, rather than focusing on the elasticity of substitution, we could have adopted Clark (1957)'s perspective and argue that the decrease in the price of goods fosters an increase in the real wage a thus a general increase in the demand for goods and services. Because productivity in the service sector is not improved by technological changes, labor input in the service sector should rise to respond to the increasing demand. However, since Goos, Maning, and Salomons (2010) find little support to this income effect hypothesis, our paper adopts a novel perspective by pointing to population aging as the main factor responsible for the increased complementary relation between personnel services and goods. This increased complementarity promotes a rise in the demand for services if the price of goods falls. So the main contribution of our paper is to show that polarization of employment at the bottom of the wage distribution responds to a demand effect linked to a progression in the demographical composition.

From a theoretical point of view, we propose a simple framework following Baumol (1967). The model provides us the necessary equation to estimate the elasticity of substitution between goods and services by age-class as well as the rationale behind the benchmark equation estimated to analyze the impact of population aging on the demand for labor input in the low-paid service sector. For the empirical part, we use the Household Budget Survey (2006) to estimate the elasticity of substitution between goods and services and the French Labor Force Survey (1993-2007) to show the polarization of employment between "lovely and lousy" jobs and the contribution of aging to this polarization process. We first underline the importance of the increase in employment in personnel services as the main determinant of 
job polarization at the bottom of the distribution. Then, we propose several tests to prove the role of aging as responsible for the increasing demand for personnel services.

The paper is organized as follows. Section2 sketches the theoretical framework. The description of the databases is provided in section 3. Section 4 motivates our assumption concerning the divergent elasticity of substitution between goods and services for seniors and young workers. Section 5 provides evidence of job polarization in the French labor market over the past 18 years. The rise in employment and wages suggests an expanding demand for jobs at the bottom of the wage distribution. These jobs appear to be essentially personnel service occupations. We show that the rise in service occupation jobs is linked to new technologies (ICT) and aging, which constitutes the first originality of our paper. Section 6 concludes.

\section{A simple model}

Suppose an economy that can be broadly divided into 2 sectors: the routine good sector, employing labor and capital to produce goods, and the low-skill personnel service sector, employing exclusively labor to produce. Because routine tasks employed in the good sector are easily programmable, they can be implemented in an equally efficient way by capital or labor. Both factors are assumed to be perfectly substitutes in the production process of routine goods. Moreover, technological progress positively affects the relative productivity of capital.

We also suppose an imperfect competitive environment, where firms determine prices by imposing a mark-up over their marginal cost. This marginal cost is closely linked to wages paid by the firm. Finally note that, technological progress does not affect the marginal productivity of labor in the personnel service sector, whereas it will deteriorate the relative productivity of labor with respect to capital in the good sector. 


\subsection{The household decision}

\subsubsection{Consumption decision}

For simplicity we assume a large representative household composed by individuals who might be employed in the good or service sector, unemployed or retired. Each individual has a different elasticity of substitution between goods and services, however, the aggregation of all individual preferences ${ }^{3}$ yields to a single utility function that the representative household maximizes subject to the aggregate budget constraint. More precisely,

$$
\operatorname{Max}_{q_{g t}, q_{s t}} U\left(q_{g t}, q_{s t}\right)=\left(q_{g t}^{\theta}+q_{s t}^{\theta}\right)^{1 / \theta} \quad \theta<1
$$

subject to

$$
p_{g t} q_{g t}+p_{s t} q_{s t}=y_{t}
$$

where $q_{g t}$ and $q_{s t}$ stand, respectively, for the quantity of goods and services and $p_{g t}, p_{s t}$ for their prices. The income of the household is given by $y_{t}$ and comes from wages earned by employed individuals, unemployment benefits earned by unemployed individuals and the retirement pension of senior individuals that do not longer work. The aggregate elasticity of substitution of the household between goods and services is given by $\epsilon=\frac{1}{1-\theta}$.

Replacing the first order conditions in the budget constraint yields the following demand for services:

$$
q_{s t}=y_{t}\left(\frac{p_{s t}^{\frac{1}{\theta-1}}}{p_{g t}^{\frac{\theta}{\theta-1}}+p_{s t}^{\frac{\theta}{\theta-1}}}\right)
$$

If we note the price index as $P_{t}=\left(p_{g t}^{\frac{\theta}{\theta-1}}+p_{s t}^{\frac{\theta}{\theta-1}}\right)^{\frac{\theta-1}{\theta}}$, equation (3) can be rewritten as follows:

$$
q_{s t}=y_{t}\left(\frac{p_{s t}^{\frac{1}{\theta-1}}}{P_{t}^{\theta}}\right)
$$

Taking logarithms on both sides of equation (4) gives the following log linear demand for services:

$$
\log q_{s t}=\log y_{t}-\epsilon \log p_{s t}+(\epsilon-1) \log P_{t}
$$

\footnotetext{
${ }^{3}$ It is above the scope of this paper to deal with aggregation issues since the unique goal of the theoretical model is to provide a rationale to the econometric estimations and results obtained in the following sections.
} 
The log linear approximation of the aggregate price index is:

$$
\log P_{t}=\alpha \log p_{g t}+(1-\alpha) \log p_{s t}
$$

where $\alpha$ stands for the share of income spent on the routine good sector (size of the good sector). Equation (5) can then be rewritten as:

$$
\log q_{s t}=\log y_{t}-\epsilon \log p_{s t}+(\epsilon-1) \alpha \log p_{g t}+(\epsilon-1)(1-\alpha) \log p_{s t}
$$

\subsubsection{Labor supply decision}

Young members of the household supply inelastically one unit of labor, and they may be employed or unemployed. Participation issues are not considered, so we assume that all young individuals participate in the labor market. Moreover, due to perfect labor mobility between sectors wages in the good and service sectors are equalized. Individuals are then indifferent between working in on one sector or another.

\subsection{Production decisions}

We consider an imperfect competitive environment, such that in both sectors the price results from a markup over the marginal cost. This marginal cost is evidently linked to the wage paid by the firm. In the routine good sector wages are assumed to equal the marginal productivity of labor. In the low-qualified service sector, marginal productivity of labor is normalized to one, but we assume that the firm pays the worker a wage equal to their outside opportunity of employment.

Inside the routine good sector, the relative productivity of capital is improved by technological progress, which improves then aggregate productivity of the good sector. Because capital and labor are substitutable in the good sector, the improvement in the relative productivity of capital yields firms to increase the relative demand of capital with respect to labor. The subsequent increases in the production of goods will be based on the increased use of capital. While technological progress rises the productivity in the good sector, the productivity of the low-skilled service sector (which employs only labor) remains unaffected and equals unity. The value of the outside opportunities of employment i.e. the unemployment allocation, 
value of leisure, etc. increases at the same pace as the aggregate productivity of the economy, that is, at the same pace as technological progress.

The production function in the routine good sector equals:

$$
q_{g t}=\left(a_{K t} K_{t}^{\rho}+a_{L t} L_{g t}^{\rho}\right)^{1 / \rho} \quad \text { with } \quad a_{K t}=\phi_{K} e^{g t} \quad \text { and } \quad a_{L t}+a_{K t}=1
$$

where $K_{t}$ and $L_{g t}$ stand for capital and labor and the growth rate of technological progress is given by $g$. An increase in $g$ improves the relative productivity of capital, which should yield a raise in the demand for this production factor. $\frac{1}{1-\rho}$ is the elasticity of substitution between labor and capital and it is assumed to be positive. Marginal productivity is given by:

$$
\begin{aligned}
& q_{g t}^{\prime}\left(L_{g t}\right)=q_{g t}^{(1-\rho)} L_{g t}^{(\rho-1)} a_{L t} \\
& q_{g t}^{\prime}\left(K_{t}\right)=q_{g t}^{(1-\rho)} K_{t}^{(\rho-1)} a_{K t}
\end{aligned}
$$

Because the marginal cost of labor is defined as the ratio between the wage and the marginal productivity of labor, i.e. $c m g_{g t}=\frac{w}{q_{g t}^{\prime}\left(L_{g t}\right)}$, and since wages paid by firms in the good sector equal the marginal productivity of labor, the marginal cost will equal unity in our case. This implies that $p_{g t}=\mu \cdot 1$, where $\mu$ stands for a mark-up.

Marginal productivity in the personnel service sector is normalized to one. These services require interpersonal and environmental adaptability as well as direct physical proximity. Productivity of labor in these services does not depend on capital intensity. We believe that normalizing to unity this productivity is not an unrealistic assumption and simplifies computations. The production function adopts a very simple form:

$$
q_{s t}=L_{s t}
$$

Because wages in the service sector equal the value of the outside opportunity of employment $^{4}$, the marginal cost in the service sector equals: $c m g_{s t}=b \cdot e^{g t}$, where $b$ can be interpreted as the unemployment allocation, the value of leisure, etc. The value of the outside opportunity of employment increases as the same pace as the aggregate productivity of the

\footnotetext{
${ }^{4}$ Rather than assuming that wages in the service sector are constant and independent of the progression of outside opportunities, we believe that it is more realistic to assume that they increase at the same pace as the technological frontier.
} 
economy. The price set by this sector is given by:

$$
p_{s t}=\mu \cdot c m g_{s t}=\mu b \cdot e^{g t} .
$$

Individuals of the representative household are perfectly mobile between sectors, so they reallocate in such a way that the marginal productivity of labor in the good sector (which corresponds to the wage paid by this sector) equals the wage paid in the personnel service sector:

$$
\begin{aligned}
w_{g t} & =w_{s t} \\
b \cdot e^{g t} & =q_{g t}^{(1-\rho)} L_{g t}^{(\rho-1)} a_{L t} \\
L_{g t} & =\left(\frac{a_{L t}}{b \cdot e^{g t}}\right)^{\frac{1}{1-\rho}} q_{g t}
\end{aligned}
$$

Taking logs of equation (15) allows to display the negative impact of technological progress in the demand for labor in the routine good sector, which corresponds well to the routinization hypothesis of Autor, Levy, and Kearney (2006), Spitz-Oener (2006), Maurin and Thesmar (2004) or Goos and Maning (2007):

$$
\log L_{g t}=\frac{1}{1-\rho}\left[\log a_{L t}-\log b-g t\right]+\log q_{g t}=\frac{1}{1-\rho}\left[\log \left(1-e^{g t}\right)-\log b-g t\right]+\log q_{g t}
$$

The demand for labor input in the routine good sector increases with the demand of goods and with the marginal productivity of labor, $a_{L t}$, which falls with $g$. Conversely it decreases with wages, which increase with the value of $b$ and the pace of technological progress.

Replacing $p_{g t}=\mu$ and $p_{s t}=\mu b \cdot e^{g t}$ in equation (7) yields:

$$
\log q_{s t}=C+\log y_{t}-(\alpha(\epsilon-1)) g t-g t
$$

where $C$ is the constant. Income always influences positively the demand for services. The impact of technological progress will be more or less important depending on the degree of substitutability between goods and services. More precisely, there is, on the one hand, a direct negative impact of growth on the production of service (term $-g t$ ), justified by the increase in wages associated with the raise in $g$. On the other hand, the impact of $-(\alpha(\epsilon-1)) g t$ will be positive or negative depending on the value of $\epsilon$. If for the representative household goods and service are complements then $0<\epsilon<1$. In this case, the term $-(\alpha(\epsilon-1)) g t$ becomes positive $((\alpha(\epsilon-1))<0)$, meaning that technological progress increases 
the demand for services. The importance of this effect is linked to the initial share, $\alpha$, of the production good sector (routine sector) in the economy. The larger $\alpha$, the more important the effect. If goods and services are substitutes, $\epsilon>1$, and the term $-(\alpha(\epsilon-1)) g t$ is negative, implying that technological progress reduces the demand of services. This reduction increases with $\alpha$. The routinization hypothesis (according to which the larger the share of routine jobs the more important the job polarization process, see Autor and Dorn (2011)) contributes to job polarization at the bottom of the job quality distribution when combined with a complementary relationship between goods and services. The question that arises then is in which cases goods and services are complements rather than substitutes. As shown latter in this paper, the demographical composition of the population in terms of age determines the aggregate elasticity of substitution between goods and services. Combining the progressive replacement of labor input in routine tasks by the relatively more productive capital with population aging, explains the increase in the proportion of employment at the bottom of the wage distribution (personnel services).

\subsection{Testable predictions}

Our model has a number of testable implications. Our belief is that, for seniors, goods and services are complementary whereas for young workers, they are more likely to be substitute. If our belief turns out to be true, population aging should yield a more complementary aggregate relationship between good and services. In this case, an acceleration of technological progress promoting the replacement of labor input in routine tasks by capital, should yield a rise in the demand for services, since the decrease in the relative price of routine goods should also promote the demand for services. We proceed by steps:

- First, a reduced form of equation (7) is estimated so as to compare the value of the elasticity of substitution between goods and services for age-heterogeneous households.

- Second, a reduced form of equation (17) will allow us to estimate the impact of aging, routinization and income on the demand for low-skilled personnel services. While the share of seniors does not explicitly appear in equation (17), we can consider this share as a proxy of the degree of complementarity or substitutability between goods and services. 


\section{Data}

Our empirical analysis begins with the estimation of a reduced form of equation (7) using one wave (2006) of the French Household Budget Survey. Then, a reduced form of equation (17) is estimated based on 18 successive waves of the French Labor Force Survey (1993 through 2010).

The aim of the Household Budget Survey (BDF) is to put together the entire household accounts: expenditure and resources of households in France (mainland and overseas departments). The study of expenditure is the traditional and central purpose of the survey: all household expenditure is recorded, the amount and nature of these expenses, broken down into a classification of about 900 budgetary items (COICOP) compatible with the classification used in the national accounts. All expenses are covered, including those not associated with the consumption of goods and services (in the sense of the national accounts): taxes and contributions, insurance premiums, major home renovation expenditure, inter-household transfers, purchase of second-hand goods, loan repayments. As well as expenses per se, the survey also collects information about non-monetary consumption: food produced for own consumption, imputed rentals, etc. Essentially, the family household budget survey collects monetary data, leaving the more specialized surveys on each item of consumption (transport, housing, leisure, holidays, etc.) to use a more qualitative approach to household behavior. Nevertheless, in order to illustrate these monetary data, some complementary questions are asked, on the financial situation as perceived by the household.

The statistical unit is the household and the reference area is all ordinary households in the whole of France (mainland and overseas departments). The survey takes place every 5 years (1979, 1984, 1989, 1995, 2001, 2006). Since 2001, expenditure has been classified according to the European classification. This differs considerably from the French classification used until 1995. For these reasons, the results of the 2001 and 2006 editions of the survey cannot yet be compared directly with those from previous years. Due to the absence of a panel and since expenditures on personnel services are only detailed in the 2006 wave, we employ only this wave.

The sample (random self-weighted sample) consists in about 20.000 dwellings in Metropolitan France, 5.000 in the overseas departments. The number of households surveyed is ultimately 
about 10.000 for Metropolitan France and 3.100 in the overseas departments.

The French Labour Force Survey (LFS) was launched in 1950, organized in 1982 as an annual survey. Redesigned in 2003, the survey is a continuous survey providing quarterly results. Participation in the survey is compulsory. The survey covers private households in metropolitan France. All 15 years old or more individuals in the household are surveyed. All weeks of the year are reference weeks. The quarterly sample is distributed among its 13 weeks. From a theoretical point of view, the sampling method consists in a stratification of Metropolitan France in 189 strata (21 French regions x 9 types of urban units), and a first stage sampling of areas in each stratum (with different probabilities, average sampling rate $=1 / 600)$. Areas contain about 20 dwellings, and among them only dwellings which are main residences are surveyed. The sample unit is the dwelling: in each sampled area, every private household living in its main residence is surveyed. Each area is surveyed six quarters consecutively. Each quarter, the sample contains 6 sub-samples: 1/6 of the sample is surveyed for the first time, $1 / 6$ is surveyed for the second time, $1 / 6$ is surveyed for the 6th (and last) time. Before 2003 the LFS was an annual survey. Every year, a third of the sample was renewed implying that each individual was interviewed only 3 times. The collection method before and after 2003 is a face-to-face interview ${ }^{5}$.

Topics covered by the LFS concern employment, unemployment, underemployment, hours of work, wages, duration of employment and unemployment (length of service), discouraged workers, industry, occupation, status in employment, education/qualification, other jobs. The French LFS provides the occupation for each employed individual, among a list of 350 possible occupations such as "gardener","messenger", "clerks in banking activities", "financial managers" ${ }^{6}$, etc. Some occupations are characterized by a very general definition and a large number of employed individuals. In this case, we disaggregate these jobs by industry ${ }^{7}$. For instance, secretaries are divided into secretaries in the food industry, in the car industry, etc ... This leaves us with 452 occupations each year.

\footnotetext{
${ }^{5}$ Since 2003 a telephone interview is employed for intermediate interrogations (2nd to 5th)

${ }^{6} \mathrm{With}$ this range of possible jobs, the wage distribution captures the low paid occupations as well as high paid jobs. However, the number of observations in top jobs is particularly low in all surveys. The sample does not capture the increase in wage inequality due to the top $1 \%$ of the wage distribution (Landais (2008)).

${ }^{7}$ Appendix A provides a full description of the data.
} 


\section{The elasticity of substitution between goods and ser- vices}

Our main claim is that population aging induces an increase in the demand of low-skilled personnel service sectors (job polarization at the bottom of the wage distribution) due to the complementary relationship between goods and services. More precisely, we believe that for seniors good and services are more complementary than for young workers. Since recent technological changes have promoted a reduction in the price of goods (routine labor in the good producing sector has been replaced by cheaper technological capital), the demand for personnel services will tend to increase if goods and services are complementary. Conversely, we expect a reduction in the demand for services if they are substitute with respect to goods. We use the Household Budget Survey 2006. We consider as senior households those composed by either two people older than 60 or a single person older than 60 . We eliminate all senior households where a younger individual lives with the couple or the person. This choice is motivated by the fact that we are considering the demand for personnel services of senior households and this demand may be influenced by the presence of a younger person in the household which can help seniors. We have more than 2540 senior households. We define a young household as one composed by one or two people aged between 30 and 45 years old and not having children (more than 1800 young household).

The survey provides information on the annual expenditures of hiring someone to do house cleaning, shopping, health care, garden care, house watch and others. Unfortunately most households, particularly young households, declare having zero expenditures on the majority of these services. House cleaning are the expenditures for which the number of households declaring a strictly positive quantity is the highest (467 senior households and 146 young households declare strictly positive house cleaning expenditures). So we will focus on this type of personnel service.

The first problem we must deal with is the lack of information concerning the number of hours worked by the personnel service employee. There is only one variable in which households declare the number of hours hired over the last two months. However there is a great number of missing observations in this variable. We solve both problems sequentially. First, since we deal with yearly expenditures, in order to compute the hourly cost we are obliged to 
assume that the number of hours worked by the personnel service employee in one year is six times the number of hours worked in two months. Second, to deal with the problem of missing data in the number of hours, we compute the average number of hours hired by different categories of households classified depending on their yearly expenditures. This average number of hours is then imputed to the households of the corresponding spending category if the number of hours is missing. This implies assuming that all households having similar house cleaning expenditures hire a similar number of hours.

Finally, to compute the hourly price paid by households for personnel services, we divide yearly expenditures by yearly hours (declared or imputed). Evidently, since yearly hours result from extrapolating the number of hours declared over the last two months to the whole year, the computed hourly price displays in many cases impossible values (too low or too high). We drop observations for which the hourly price is below five euros ${ }^{8}$ and above 150 euros. The final sample of households declaring an strictly positive house cleaning expenditure (and paying thus a strictly positive hourly price) is reduced by more than a half (200 senior households and 46 young households). For households (young and old) whose cleaning expenditures equal zero we consider that the hourly price equals the 2006 minimum wage which was equal to 6.9285 euros.

We have now all the required information to estimate a reduced form of expression (7). Because we are working with cross-sectional data, there is no variation at all in the general consumption price index $P_{t}$. This term is then included in the constant and our simple estimation reduces to:

$$
\log q_{s}=C+\log y-\epsilon \log p_{s}+\mu
$$

where $\epsilon$ stands for the elasticity of substitution, $C$ for the constant, $y$ for the income, $p_{s}$ for the hourly price of house cleaning services and $\mu$ for the error term. Income ${ }^{9}$ and hourly price vary among workers.

Table 1 summarizes our estimations. Columns 1 and 2 provide the estimation of the elastic-

\footnotetext{
${ }^{8}$ Even if this bound is below the French minimum hourly wage, wages paid to a household employee are partially deductible from taxes in France. Because we believe that some households may declare the after tax wage they pay we set this lower bound to five euros.

${ }^{9}$ Income refers to permanent income and results from the sum of the retirement pension (if there is), salary or income from a self-entrepreneur.
} 
ity of substitution (coefficient associated with $p_{s}$ ) when we exclusively consider the sample of households declaring strictly positive house cleaning expenditures. The size of the sample is so small that we obtain very poor estimates on the elasticity of substitution. For seniors, coefficients are negative, smaller than 1 but not significant ( $R^{2}$ equals $0.2 \%$ ). For young household we are only working with 46 observations which makes us very cautious concerning the interpretation of the obtained coefficients. In columns 3 and 4 we include also households who do not employ cleaning services (this constitutes also an information that should be considered). The size of the sample increases to 2398 observations for seniors and 1804 observations for young workers. However, it must be notice that only $10 \%$ of senior's observations and $3 \%$ of young's observations are strictly positive ${ }^{10}$. Our sample is thus left censored. The estimated elasticity is significant and below unity for seniors while it is significant and above unity for young households. That is goods and services are complements for seniors and substitutes for young households.

Finally, even if our estimations reveal that the elasticity of substitution between goods and services is always larger for young households than for senior households, in some cases, coefficients remain quite close. In order to test if they are significantly different we consider a pooled sample including young and old households. We add to equation (18) an interacted term resulting from multiplying the hourly price and a dummy taking the unitary value when considering a senior worker. Table 2 reveals that this interacted term arises as positive and significant ${ }^{11}$. To determine the particular elasticity associated with seniors the coefficient of the individual variable must be added to that of the interacted variable. We find that the coefficient associated with $p_{s}$ is significant above one ${ }^{12}$ (in absolute terms). When adding this coefficient with the one of the interacted variable, we obtain a value below one, confirming the idea that goods and services are complements for seniors and substitutes for young

\footnotetext{
${ }^{10}$ In order to deal with left-censored observations we propose a tobit estimation. Displayed coefficients in columns 5 and 6 correspond to the average marginal effects. They appear to be lower for seniors than for young households. The likelihood ratios chi-square with p-values equal to zero tell us that our model as a whole fits significantly better than an empty model.

${ }^{11}$ The value of the joint F-test is significant at the 1 percent level, implying that the hypothesis of equal elasticity of substitution among households has to be rejected and there exists an age specific effect.

${ }^{12}$ Actually -1 does not belong to the confidence interval associated with -1.247 which confirms that the coefficient is significantly above 1 in absolute terms.
} 
Table 1: Elasticity of substitution between goods and services. Budget Household Survey 2006 .

\begin{tabular}{|c|c|c|c|c|c|c|}
\hline \multirow[b]{2}{*}{ Variables } & \multicolumn{2}{|c|}{ Positive expenditure } & \multicolumn{2}{|c|}{ All households } & \multicolumn{2}{|c|}{ All households. Tobit estimation } \\
\hline & Seniors & Young & Senior & Young & Senior & Young \\
\hline \multirow[t]{2}{*}{$\mathrm{y}$} & 0.0102 & $0.209 * *$ & $0.133^{* * *}$ & $0.387^{* * *}$ & $0.714^{* * *}$ & $6.095^{* * *}$ \\
\hline & $(0.0534)$ & $(0.0868)$ & $(0.04566)$ & $(0.041255)$ & $(0.2555)$ & $(0.83123)$ \\
\hline \multirow[t]{2}{*}{ ps } & -0.0529 & $-0.255^{* *}$ & $-0.946^{* * *}$ & $-1.017^{* * *}$ & $-2.5825^{* * *}$ & $-3.370 * * *$ \\
\hline & $(0.0775)$ & $(0.0958)$ & $(0.07253)$ & $(0.10391)$ & $(0.29751)$ & $(0.80874)$ \\
\hline Constant & YES & YES & YES & YES & YES & YES \\
\hline Observations & 199 & 46 & 2,398 & 1,804 & 2,398 & 1,804 \\
\hline R-squared & 0.002 & 0.287 & 0.0670 & 0.0952 & & \\
\hline Pseudo $R^{2}$ & & & & & 0.0187 & 0.072 \\
\hline LR $\operatorname{chi} 2(2)$ & & & & & 81.38 & 103.13 \\
\hline Prob $>$ chi 2 & & & & & 0.0000 & 0.0000 \\
\hline
\end{tabular}

Standard errors in parentheses

$* * * p<0.01, * * p<0.05, * p<0.1$ 
Table 2: Elasticity of substitution between goods and services. Pooled sample. Budget Household Survey 2006.

\begin{tabular}{lc}
\hline Variables & All households \\
\hline $\mathrm{y}$ & $0.216^{* * *}$ \\
& $(0.0317)$ \\
$\mathrm{ps}$ & $-1.247^{* * *}$ \\
& $(0.06153)$ \\
& $0.3329 * * *$ \\
ps·senior & $(0.02741)$ \\
& 235.67 \\
F-test & $(0.0000)$ \\
& $\mathrm{YES}$ \\
Constant & 4202 \\
Observations & 0.0945 \\
$R^{2}$ & \\
\hline Standard errors in parentheses \\
$* * * p<0.01, * * p<0.05, * p<0.1$ \\
\hline
\end{tabular}

households.

In sum, our estimations suggest that goods and services are complements for seniors while they become substitutes when considering young people.

\section{Job polarization and aging on French microdata}

In this section, we provide evidence that France has experienced a job polarization over the past decades. We essentially focus on the bottom of the wage distribution, where we analyze the presence of service occupations. The following section will consider the role of population aging in this polarization process. 


\subsection{Change in the employment structure in France}

The French LFS allows us to have a look at trends in the quality of jobs. As in Goos and Maning (2007), quality is proxied by the median hourly wage for each job at the beginning of the period.

We first relate the job quality in 1993 with the average subsequent change in log employment from 1993 through $2010^{13}$. Figure 1 presents the average change in log employment in the 1993-2010 period (Y-axis) for each job quality (proxied by its median wage in the X-axis). The size of the circles denotes the employment level in 1993. We also report a quadratic fit of the average employment growth by job quality. Panel $(i)$ of Figure 1 suggests an Ushaped relationship between employment growth and job quality ${ }^{14}$. The quadratic fit can be represented as follows:

$$
\begin{aligned}
d(\log \text { employment })= & \alpha \log w_{1993}+\beta\left(\log w_{1993}\right)^{2}+C \\
d(\log \text { employment })= & -0.6384738 \log w_{1993}+0.0373618\left(\log w_{1993}\right)^{2}+2.734133 \\
& \left(0.0009208^{* * *}\right) \quad\left(0.0000521^{* * *}\right)
\end{aligned}
$$

where standard errors are reported in parentheses ${ }^{15}$. While the coefficient of the linear term, $\log w_{1993}$, arises as negative and significant, the coefficient associated with the quadratic term, $\left(\log w_{1993}\right)^{2}$, is positive and significant, confirming the U-shaped progression (polarization ) of the employment structure between 1993 and 2010. Over the past decades, middling jobs have been characterized by a low employment growth while the rise in employment has been larger for jobs at the bottom and at the top of the wage distribution.

At the lower end of the job quality distribution, two jobs are characterized by a high employment level in 1993 and a strong subsequent employment growth. These large circles correspond to occupations related to child care and house cleaning. More generally, low paid

\footnotetext{
${ }^{13}$ Unfortunately, we could not use LFS prior to 1993 because of a drastic change in industry classification. It was not possible to obtain consistent industry codes over time. Since some jobs are defined as a specific occupation in a specific industry, this prevents us from using pre-1993 surveys.

${ }^{14}$ We choose to consider here the change in log employment over the 1993-2010 period as in Goos and Maning (2007). Autor and Dorn (2011) examine the change in employment share. We check that the relationship between job quality and change in employment share is still U-shaped, thereby suggesting a job polarization.

${ }^{15}(* * *)$ : significant at $1 \%$. (**): significant at $5 \%$. (*): significant at $10 \%$
} 
jobs in 1993 with rising employment between 1993 and 2010 are service occupations. This is clearly observed in Panel (ii) of Figure 1 which reveals that, as soon as we do not include in the analysis personnel service occupations, the U-shape curve disappears. Finally, in Panel (iii), we observe that the increased demand for jobs at the bottom of the wage distribution has promoted a more important increase in wages for these jobs than for middle (or top) jobs. The three figures together send a clear message: between 1993 and 2010, positions at the bottom or at the top of the wage distribution have benefited from larger increases in employment than positions at the middle of the distribution. This is particularly intensive for positions at the bottom of the distribution (personnel services) which have also experienced the largest increases in wages.

One might think that the feminization of employment can explain this job polarization, with women accounting for the growth in relatively low-paid occupations. But, as Figure 2 shows, one observes similar patterns for male and female employment considered separately in the 1993-2010 period. Results are not modified with respect to the pooled sample. Jobs at the bottom or at the top of the wage distribution have benefitted from larger growth rates than jobs at the middle of the distribution, determining an U-shape progression of the employment structure.

In sum, Figures 1 and 2 support the view that job polarization has occurred over the past decades in France and that the increase in the employment share at the bottom of the wage distribution comes mainly from personnel services occupations. This can also be seen from Table 3 that ranks occupations from highest-paid to lowest-paid. For each occupation, Table 3 reports the average log change in employment and wage. Among the fastest expanding occupations (panel (a) of Table 3) are managers and executives but also the lowest-paid jobs (panel (c)) such as child care and transportation services. The largest declines in employment (panel (b)) are observed for middling occupations such as secretaries, office clerks and some skilled workers in specific industries. Panel (d) of Table 3 reports the average change in log employment over 1993-2007 for the top 10\% jobs (ranked by the median 1993 wage), bottom $10 \%$ and middling jobs (identified as job in the 45-55\% percentiles of the 1993 wage distribution). The table confirms the fast employment growth at the top and bottom of the job quality ladder while middling occupations have been characterized by a decline in employment. Furthermore, most of the employment growth observed at the bottom of the 
(i): Benchmark

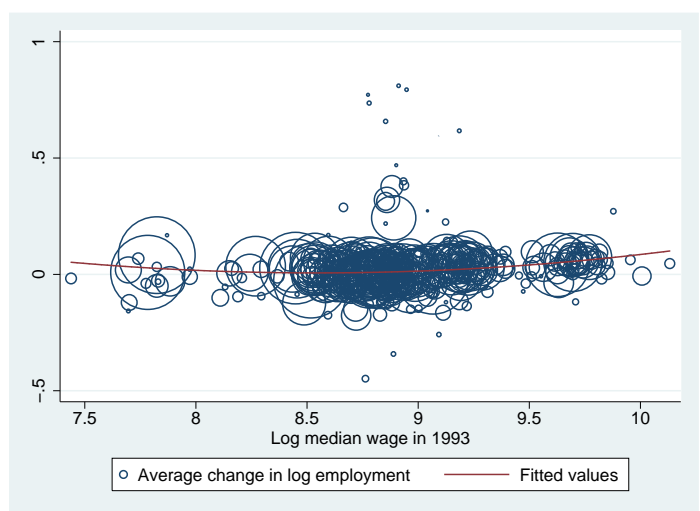

(ii): No personnel services

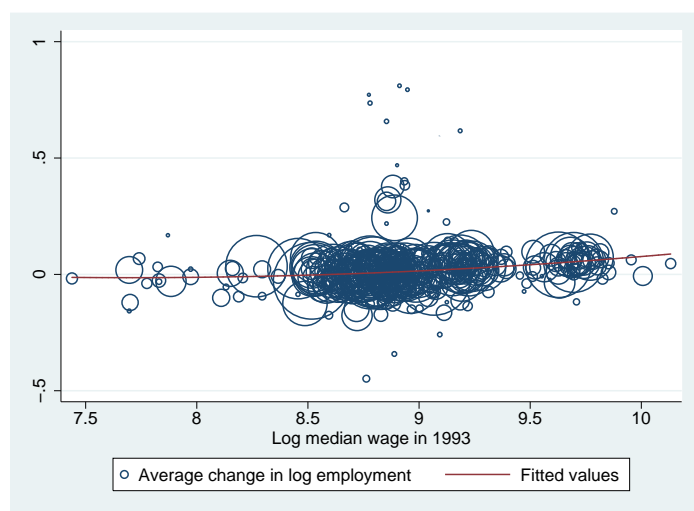

(iii): Wages

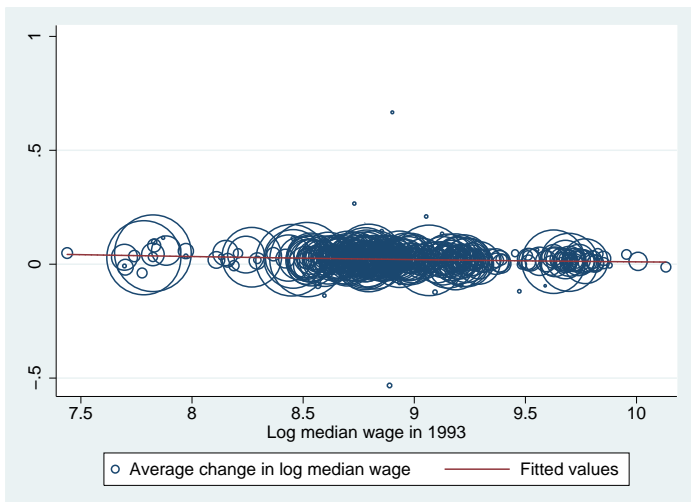

Figure 1: Average employment and wage growth by job median wage (1993-2007). X-axis: Log-median wage in 1993. The size of the circles corresponds to the employment level in 1993. Y-axis: Average growth rate of employment between 1993 and 2010. 
(i): Benchmark (women)

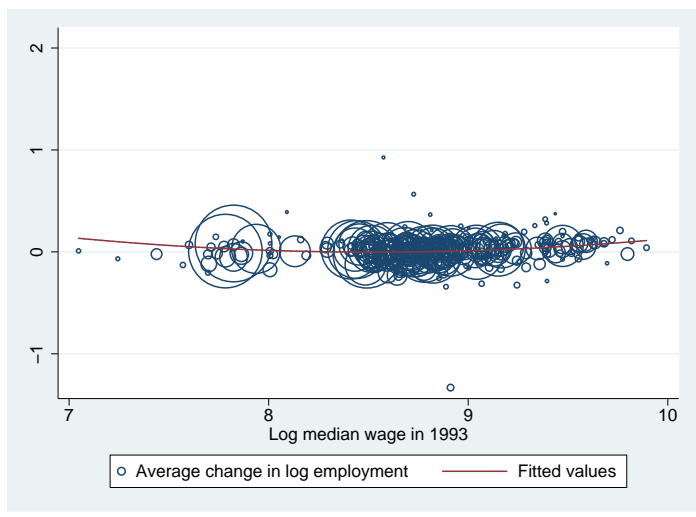

(ii): Benchmark (men)

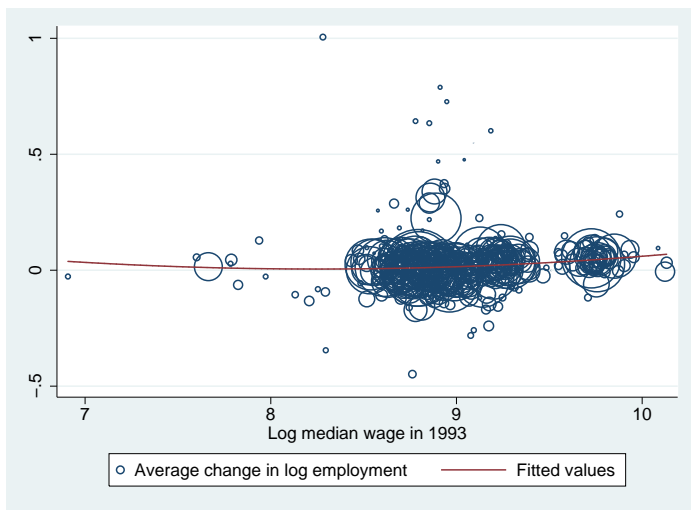

Figure 2: Average employment growth for men and women by job median wage (1993-2007). X-axis: Log-median wage in 1993. The size of the circles corresponds to the employment level in 1993. Y-axis: Average growth rate of employment between 1993 and 2010.

wage distribution comes from service occupation jobs.

These facts, also found by Autor and Dorn (2011) on US data, motivate our investigation on service employment. We investigate in the next section how aging, interpreted as a proxy of an increased complementary relationship between goods and services, has affected the demand for services and thus employment in the service sector over the past 18 years.

\subsection{Growth in service employment and aging}

In this subsection, we analyze the relationship between aging and growth in service employment after including control variables. As in Autor and Dorn (2011), our empirical investigation relies on a panel of small geographical units: the departments. We consider 96 departments included in 21 French regions. Our sample spans 1993-2010, which yields a panel data of more than 1700 observations. Using the department level rather than the regional level, allows us to consider a larger sample.

In each department, each year, we compute the share of service employment in total employment. We then compute the yearly change in this share and finally we employ these values to compute the change in the share of services employment in total employment for the periods 1993-2001 and 2002-2010. Since we have data on 18 years, we consider intervals of 9 years because we believe is long enough to allow for an adjustment of the employment 
Table 3: Change in log employment (dlnN) over 1993-2010 for occupations ranked by their median 1993 wage (lnW1993)

\begin{tabular}{|c|c|c|}
\hline & $\ln W_{1993}$ & $d \ln N$ \\
\hline \multicolumn{3}{|l|}{ (a) Top paying jobs } \\
\hline Flying personnel & 10.13204 & .0465518 \\
\hline Managers in big firms, administrative, financial or sale department & 10.006 & -.006904 \\
\hline Technical managers in big firms & 9.954719 & .0624228 \\
\hline Engineer and executive managers & 9.87817 & .2712399 \\
\hline \multicolumn{3}{|l|}{ (b) Middling occupations } \\
\hline Office clerk in accounting and financial department, transportation industry & 8.834143 & -.0116572 \\
\hline Office clerk in accounting and financial department, food industry & 8.836745 & .0167217 \\
\hline office clerks, misc, intermediate good industry & 8.838068 & -.00573 \\
\hline skilled worker in weather-stripping & 8.839276 & -.0208104 \\
\hline skilled worker in extraction & 8.839276 & -.1188045 \\
\hline Secretaries, engineering industry & 8.839276 & -.0439425 \\
\hline unskilled worker in sorting, wrapping and delivery activities, engineering industry & 8.844096 & -.0244403 \\
\hline Secretaries, car industry & 8.847156 & -.0353632 \\
\hline Secretaries, food industry & 8.853665 & -.0379203 \\
\hline \multicolumn{3}{|l|}{ (c) Lowest paying jobs } \\
\hline Bakery, butchery employee & 7.696213 & .0191935 \\
\hline Cleaners, financial industry & 7.699993 & -.1208007 \\
\hline Transportation services in health industry & 7.740664 & .0678637 \\
\hline Cleaners, consumption goods industry & 7.775527 & -.0386493 \\
\hline Housework employees in private homes & 7.783224 & .0086223 \\
\hline Child care & 7.824046 & .0827386 \\
\hline \multicolumn{3}{|l|}{ (d) } \\
\hline top $10 \%$ & 9.618954 & .0466335 \\
\hline middling occupation (45-55\%) & 8.827257 & -.0040566 \\
\hline bottom $10 \%$ & 8.074184 & .0277598 \\
\hline service occupations & 8.30726 & .0376211 \\
\hline
\end{tabular}


structure following a modification in the demand due to a demographical change. For each department, each of the two intervals constitutes our dependant variable. With 96 departments and 2 changes in service employment share (1993-2001 and 2002-2010) yields a panel data of 192 observations.

Our empirical exercise mimics Autor and Dorn (2011)'s investigation on US commuting zones. We extend their analysis on French data and lay stress on the demand shift associated with aging. The estimated equation is

$$
d\left(\frac{N_{i, t}^{\text {service }}}{N_{i, t}}\right)=\alpha+\beta \text { old }_{i, t-1}+\gamma X_{i, t-1}+e_{i, t}
$$

where $d\left(\frac{N_{i, t}^{\text {service }}}{N_{i, t}}\right)$ denotes the change in service employment share $\left(\frac{N_{i, t}^{\text {service }}}{N_{i, t}}-\frac{N_{i, t-1}^{\text {service }}}{N_{i, t-1}}\right)$ in department $i$ and period $t-(t-1)$. Service jobs include the following occupations : house cleaning, child care, janitors, .... Appendix B provides the list of service occupations. We adjust standard errors for clustering of observations at the department level.

Our paper explores the view that the rise in service employment at the bottom of the wage distribution is demand driven, in particular, by aging individuals. This effect is measured by the share of retired individuals aged 60 and more in the total population, denoted old $_{i, t-1}$ in department $i$ at the start of the period $[t-1, t]$. This share is taken at the start of the period value in order to capture the exogenous effect of aging on the change in service employment share. If our hypothesis is confirmed by the data, we expect $\beta>0$. Our benchmark equation equation stacks the two time periods covering the interval 1993 through 2010, and includes a full set of time effects, department effects, as well as the start-of-period values of five additional explanatory variables ${ }^{16}\left(\operatorname{denoted} X_{i, t-1}\right)$ :

- the share of managers ${ }^{17}$ in department $i$. This variable seeks to capture the income effect invoked by Mazzolari and Ragusa (2008) as responsible of the increase in the demand for low-skilled personnel services. This variable also controls for the effect

\footnotetext{
${ }^{16}$ By taking the start-of the 9 year period value, we essentially avoid erogeneity issues.

${ }^{17}$ The INSEE (National Statistical Institute) classification includes the following list of managers: engineers, managers from the public and private sector, professors, scientific occupations, administrative managers, marketing managers, journalists, hobs in arts and life performance.
} 
underlined in Manning (2004) according to whom, employment of low-skilled is increasingly dependent on physical proximity to high-skilled.

- the share of routine jobs. This variable proxies the technological change stressed in Autor and Dorn (2011). For these authors, recent technological change results in a large automation of "middle qualified" routine tasks. The computerization of these jobs put "medium-skilled" workers out of employment. They then accept service occupation jobs that are expensive and cumbersome to computerize. We identify routine occupations in the list of our 452 jobs. Contrary to other papers in the subject we do not have a Dictionary of Occupational Titles allowing us to determine the task composition of each occupation. We are thus obliged to classify jobs as either routine or non routine (see Appendix B). For our benchmark regression we adopt a tight definition of routine (so as to be sure that all considered jobs mainly include routine tasks). However we also implement a robust test where we consider as routine a larger set of jobs. In all cases, we expect a positive estimated coefficient.

- the unemployment rate measures local labor market conditions. The expected sign of this coefficient is unknown a priori. In principle, when the unemployment rate is high, the average level of income that can be spent on service activities is weak, which should decrease the demand of personnel services (such as gardeners, house cleaners or child care, etc). On the other hand, an initial high unemployment rate may promote a more intensive labor reallocation towards the service sector. Depending on which effect dominates the coefficient will be positive or negative.

- the share of manufacturing jobs is the second indicator of local labor market conditions. To avoid collinearity problems, we eliminate from the set of manufacture jobs all jobs that are already included as routine in the regression. So in the share of manufacture jobs we actually find only the share of non routine jobs in the manufacture sector. Again the expected sign of this variable is in principle ambiguous. On the one hand, it controls for a composition effect. Service sector is likely to expand less rapidly if there is a large share of non routine manufacturing employment. On the other hand, it may also capture an income effect. 
- the share of female active labor force constitutes another potential demand shifter. Many services, such as restaurant meals or housekeeping, serve as substitutes for household production. Hence, higher female labor force participation might be expected to raise demand for these services (see Manning (2004) or Mazzolari and Ragusa (2008)). On the other hand, many of the personnel service jobs are implemented by women so a lower female labor force participation may prevent from providing some personnel services.

All variables are computed using French LFS, except from the share of old workers and the unemployment rate, that are taken from the French Institute of Statistics database (INSEE). Table 4 reports estimated results on the departmental panel data. It reveals a significant positive relationship between aging and growth in service employment. Column (1) simply reveals a positive correlation between the initial share of old people in the department and the growth rate over the following nine years in the proportion of workers employed in the personnel service sector. Column (2) includes department and time specific dummies. Department dummies allow to capture time unchanging determinants in the share of service employment across departments, such as geographical characteristics (weather, sea, proportion of urban and rural areas). Time dummies allow to capture time changing determinants in the share of service employment common to all departments ${ }^{18}$. In Column (2) we also include as a covariate the share of old workers in the department but also a major alternative demand shifter: the share of managers in the department. By controlling for managers, we aim at capturing the income effect invoked in Manning (2004) or Mazzolari and Ragusa (2008). The coefficient associated with the proportion of seniors remains positive and significant, whereas that associated with managers arises as positive but not significant. The increase in the employment share in the personnel service sector does not seem to respond to an income effect ${ }^{19}$ coming from the increased presence of highly-paid managers in the department, but rather from a demand shift explained by an aging population.

\footnotetext{
${ }^{18}$ This mainly concerns political measures such as the APA or credit d'impot

${ }^{19}$ We have also implemented the regression considering as a explanatory variable the share of older that used to be employed in manager positions, so as to capture an income effect coming from richer retired workers. This regression is available upon request. We conclude that there is no significant difference in the impact on the share of service employment between seniors that used to be managers and the rest of seniors. This suggests that there is no significant income effect coming from the income power of seniors.
} 
Table 4: Change in service employment share and aging: Benchmark regression at the regional level (1993-2010)

\begin{tabular}{|c|c|c|c|c|c|c|}
\hline Variables & (1) & $(2)$ & $(3)$ & $(4)$ & $(5)$ & (6) \\
\hline \multirow[t]{2}{*}{$\operatorname{old}_{t-1}$} & $0.0103^{* * *}$ & $0.142^{* *}$ & $0.137 * *$ & $0.118^{* *}$ & $0.118^{* *}$ & $0.119^{* *}$ \\
\hline & $(0.00107)$ & $(0.0607)$ & $(0.0611)$ & $(0.0581)$ & $(0.0583)$ & $(0.0586)$ \\
\hline \multirow[t]{2}{*}{ Routine $_{t-1}$} & & & $0.0249^{*}$ & $0.0326^{* *}$ & $0.0320^{* *}$ & \\
\hline & & & $(0.0148)$ & $(0.0145)$ & $(0.0147)$ & \\
\hline \multirow[t]{2}{*}{ Unemployment $_{t-1}$} & & & & -0.00565 & -0.00605 & -0.00377 \\
\hline & & & & $(0.0547)$ & $(0.0542)$ & $(0.0541)$ \\
\hline \multirow[t]{2}{*}{ Female $_{t-1}$} & & & & & -0.00873 & -0.00929 \\
\hline & & & & & $(0.0106)$ & $(0.0107)$ \\
\hline \multirow[t]{2}{*}{ Manufacture $_{t-1}$} & & & & $0.0339^{* * *}$ & $0.0342^{* * *}$ & \\
\hline & & & & $(0.0108)$ & $(0.0108)$ & \\
\hline \multirow[t]{2}{*}{ Managers $_{t-1}$} & & 0.0231 & 0.0227 & $0.0273^{*}$ & $0.0274^{*}$ & $0.0278^{*}$ \\
\hline & & $(0.0150)$ & $(0.0146)$ & $(0.0149)$ & $(0.0151)$ & $(0.0155)$ \\
\hline \multirow[t]{2}{*}{ General routine $_{t-1}$} & & & & & & $0.0267^{*}$ \\
\hline & & & & & & $(0.0149)$ \\
\hline \multirow[t]{2}{*}{ General manuf $_{t-1}$} & & & & & & $0.0353^{* * *}$ \\
\hline & & & & & & $(0.0113)$ \\
\hline Time dummies & $\mathrm{NO}$ & YES & YES & YES & YES & YES \\
\hline Department dummies & $\mathrm{NO}$ & YES & YES & YES & YES & YES \\
\hline Observations & 192 & 192 & 192 & 192 & 192 & 192 \\
\hline R-squared & 0.291 & 0.518 & 0.532 & 0.568 & 0.571 & 0.566 \\
\hline \multicolumn{7}{|c|}{ Standard errors in parentheses } \\
\hline \multicolumn{7}{|c|}{$* * * p<0.01, * * p<0.05, * p<0.1$} \\
\hline
\end{tabular}


What about the role of the routinization hypothesis? According to our theoretical framework, the presence of labor input in routine jobs (that will be progressively replaced by technological capital) yields an increase in the proportion of service employment only if goods and services are complements, i.e. the decrease in the relative price of goods promoted by the progressive substitution of labor by capital in the good sector promotes an increase in the demand for services only if goods and services are complements. Our setup proxies the degree of complementarity between goods and service using the share of old people in the population. As previously estimated in section 4, for households older than 60 years old, goods and services are complements, therefore we believe that the share of people older than 60 in the total population represents a good proxy of the aggregate elasticity of substitution.

On the other hand, the progressive replacement of labor input in routine tasks has favored a labor force reallocation towards jobs at the bottom of the wage distribution, whose demand is growing (if goods and services are complements). Column (3) introduces the employment share in routine jobs as an additional control variable. This new variable arises as positive and significant, but displays a lower coefficient value than the share of old people which remains positive and significant. Our estimations confirm then that in departments where the initial share of people employed in routine jobs was high the subsequent increase in the proportion of workers employed in the personnel service sector was more important. This finding is coherent with the existing literature on job polarization.

Column (4) introduces two additional variables in order to control for the local labor market conditions: the unemployment rate and the share of non routine manufacture employment in the department. Whereas the former arises as not significant, the proportion of non routine manufacture employment and the proportion of managers are positive and significant, which suggests that we manage to control for an income effect. The routinazation hypothesis still holds and the proportion of old people in the department keeps the highest positive and significant coefficient.

Column (5) controls also for female labor force participation. However this variable does not display a significant role, and the significance and size of the rest of the coefficients remains essentially unaffected. Finally, in column (6) we adopt a more general definition of routine jobs (including a larger number of positions). Previous results remain robust to this 
definitional modification ${ }^{20}$.

In sum, our estimations confirm that polarization of employment at the bottom of the wage distribution results from a demand shift effect coming from a modification in the demographical composition. This effect seems to overcome the potential impact of other demand shifter such as the share of highly paid managers in the department or female labor force participation. As already remarked, by setting the value of the explanatory and control variables at the beginning of the 9-year period, we avoid endogeneity issues.

\section{Conclusion}

The main contribution of this paper is to provide a potential explanation for the increased demand for labor at the bottom of the wage distribution over the pas decades. While most of the literature agrees on the major role of ICT as a determinant of the job polarization process at the top of the wage distribution, no consistent explanation has been provided for the polarization at the bottom of the distribution. In this paper we claim that this polarization results from a demand shift effect due to population aging. More precisely, using the French Household Budget Survey we estimate first the elasticity of substitution between goods and services for age heterogenous households (young and old). Our estimations reveal that goods and services are rather complementary for seniors and substitutes for young households. Second, we proceed to show, that this complementary relation induces a demand shift if population ages, promoting the increase in labor at the bottom of the wage distribution. The diffusion of ICT over the past decades has fostered a decrease in the relative price of goods. This reduction in the relative price of goods combined with population aging, have promoted an increase in the demand for personnel services and thus in the demand for labor at these positions. Based on the French Labor Force Survey 1993-2010, our estimations confirm the major contribution of aging to job polarization at the bottom of the wage distribution.

\footnotetext{
${ }^{20}$ All regressions in table 4 have also been implemented considering as a explanatory variable the share of old people having a high education diploma or having previously occupied a manager position (available upon request), so as to test the existence of an income effect. This explanatory variable arises as not significant.
} 


\section{Appendix A: Definition of jobs}

Farmers, civil servants, military and clergymen are excluded from the sample. All jobs related to these categories are dropped from the sample. Some occupations are characterized by a large employment and a vague definition. Following Goos and Maning (2007), each of the following jobs is defined as the specific occupation in a particular industry (15 sectorial activities) : secretary; clerks in financial departments and accounting; cleaners; clerks in various departments; unskilled workers in mechanical works, monitoring and assembly line; courier, messenger; warehouseman, unskilled workers in shipping and transportation; unskilled worker in sorting, wrapping and delivery activities; drivers; executive workers in small firms in finance or administration; storekeeper. The 15 sectors are : Food industry; Consumption Goods; Car industry; Engineering industry; Intermediate goods; Energy; Construction; Trade and repairing; Transportation; Financial activities; Real estate; Services to firms; Services to private individuals; Education, health, social services; Administration. Some jobs may have disappeared while new ones are popping up. The French LFS has modified the job classification in 2003 in order to take into account the evolution of occupations. We paid attention to have a consistent definition of jobs through the 15 years of our sample. There are no new occupations that cannot be included in the pre-2003 classification.

\section{Appendix B: Data for regressions}

In the sample survey, 96 departments regions are considered. In all regressions, departments are weighted by their total population. Jobs included in the service occupation are:

1. waiter / waitress

2. hotel staff

3. receptionist

4. accompanying services

5. janitor

6. cleaner in services for private individuals 
7. gardener

8. cleaner and staff in private homes

9. child care, family worker

10. auxiliary nurse

11. workers in hospitals

12. ambulance driver

13. manicure, beautician (employee)

14. hairdresser (employee)

15. manicure, beautician, hairdresser (self-employed)

16. worker on various services to private individuals

For want of an accurate description of the tasks involved in each job, we choose among the list of 452 occupations a set of jobs considered as "routine". In order to establish this list, we look at routine jobs identified in Autor and Dorn (2011), Spitz-Oener (2006). Are considered as "routine jobs" the following occupations : typist, keyboarder; operator on computer; office clerk in accounting and financial department in all industries; office clerk in misc. departments in all industries; unskilled workers in mechanics; unskilled workers in extraction; unskilled workers in wrapping, delivery. We check that these jobs are characterized by a 1993 median range that lies in the middle of the 1993 wage distribution (40-60\% range).

\section{References}

Autor, D., and D. Dorn. 2011. "The Growth of Low-Skill Service Jobs and the Polarization of the U.S. Labor Market." MIT Discussion Paper.

Autor, D., L. Katz, and M. Kearney. 2008. "Trends in the U.S. Wage Inequality: ReAssessing the Revisionists." Review of Economic and Statistics 90 (May): 300-323. 
Autor, D., F. Levy, and M. Kearney. 2006. "The Polarization of the US Labor Market." American Economic Review 96 (2): 189-194 (January).

Baumol, W. 1967. "Macroeconomics and Unbalanced Growth: The Anatomy of Urban Crisis." American Economic Review 62:415-426.

Cheron, A., F. Langot, and E. Moreno-Galbis. 2011. "Labor market institutions and technological employment." Economica 78 (309): 159-186.

Clark, C. 1957. The Conditions of Economic Progress. Macmillan. London.

Goos, M., and A. Maning. 2007. "Lousy and Lovely Jobs: the Rising Polarization of Work in Britain." Review of Economics and Statistics 89 (1): 118-133 (February).

Goos, M., A. Maning, and A. Salomons. 2010. "Explaining Job Polarization in Europe: The roles of Technology and Globalization." Mimeo.

Landais, C. 2008. "Top Income in France: Booming Inequalities." Paris School of Economics, Mimeo.

Lemieux, T. 2006. "Increasing Residual Wage Inequality: Composition Effects, Noisy Data or Rising Demand for Skill?" American Economic Review 96 (3): 461-498.

Manning, A. 2004. "We Can Work It Out: The Impact of Technological Change on the Deamnd for Low-Skill Workers." Scottish Journal of Political Economy 51:581-608.

Maurin, E., and D. Thesmar. 2004. "Changes in the Functional Structure and Demand for Skills." Journal of Labor Economics 22 (3): 639-664.

Mazzolari, F., and G. Ragusa. 2008. "Spillovers from High-Skill Consumption to Low-Skill Labor Markets." IZA Discussion Paper.

Spitz-Oener, A. 2006. "Technical Change, Job Tasks and Rising Educational Demands: Looking Outside the Wage Structure." Journal of Labor Economics 24 (2): 235-270. 